\title{
Obstetric Safety: The Security Apparatus Enhanced the Self-Efficiency of Medical Students in Vaginal Birth Practice in a Simulation Trial
}

\author{
Kitti Krungkraipetch ${ }^{1}$ \\ ${ }^{1}$ Faculty of Medicine, Burapha University, Chonburi, Thailand \\ Correspondence: Kitti Krungkraipetch, 169 Longhad Bangsaen road, Sansuk district, Faculty of Medicine, \\ Burapha University, Chonburi 20131, Thailand. Tel: 66-38-386-554. E-mail: kitti@go.buu.ac.th
}

Received: May 19, 2020 Accepted: June 2, 2020 Online Published: June 16, 2020

doi:10.5539/gjhs.v12n8p176

URL: https://doi.org/10.5539/gjhs.v12n8p176

\begin{abstract}
Currently, the safety of patients is an integral part of clinical practice, especially within medical schools. The safety device and the environment had to be concerned when medical education modules were set up. One of the most worriers in obstetrical practice among undergraduates was vaginal birth training. The inadequate safety instrument in training made students loss of their self-reliance and competence. This study aimed to test the effect of a new safety apparatus on the self-confidence and clinical performance of undergraduates on vaginal birth training. The medical students were randomized to this sample and split into two groups for two vaginal birth simulation stations; convention and intervention. The participants' self-confidence assessment was carried out at the end of trial. In addition, clinical performance ratings on vaginal birth simulation were analyzed by experts during the experiments. There was 40 medical students attended to this trial and found a significant statistical increment in GSE and CPAT scores in the intervention trial. All volunteers were satisfied with the new safety equipment and more confident to taking care of mothers in vaginal birth practices. We concluded that this innovation could boost the confidence of medical students in vaginal birth practices and increase their clinical performance in simulation. However, it needs to be checked again in the workplace.
\end{abstract}

Keywords: self concept, parturition, obstetrics, undergraduate, invention

\section{Background}

Back in the days when researchers and friends were medical students, we sometimes heard jokes about "Newborns dropping into the garbage" caused by undergraduates on vaginal delivery practices. At that time, we always talked about it with fun, but in fact it was something that we were all worried about when we had to help give birth, particularly in the first case of training. In fact, the issue of baby drops often occurred in the workplace, especially in the field of job training, but most of them were ignored and had no serious interest in solving the problem. While this concern was of low incidence, it may have caused significant health complications in certain cases, such as intracranial hemorrhage, fractures, and extreme laceration. Previous data showed trauma to newborns resulting from in-hospital falls of 1.6 per 10,000 deliveries (Monson, Henry, Lambert, Schmutz, \& Christensen, 2008). Four of 14 cases were in the delivery room, and one patient had a depressed skull fracture. Furthermore, there was no protocol to avoid such errors. This meant that about $30 \%$ of the cases occurred in the birth room. Recent birth data from the office of the National Economic and Social Development Board in Thailand reported 702,755 births in 2017 (Marchetti et al., 2012) Therefore, there could have been 37.25 newborn falls every year in the delivery room, or one baby fell in the birth room every 10 days.

There was little evidence of infant-fall avoidance, according to the literature review, and the occurrence reports in the past were lower than expected. Earlier research centered on the processes of nursing care and the evaluation of risk scoring for this problem (Abike et al., 2010; Galuska, 2011; Hantske, 2015; Helsley, McDonald, \& Stewart, 2010). No safety instrument data were available for prevention of newborn falls, particularly in undergraduate training. My consultants and I checked the birth bed configurations in hospital training centers for undergraduates in the eastern part of Thailand and found no newborn-fall security equipment. There was only small utensil that was used to collect blood and amniotic fluid. It could not protect the fall of the newborn in practice. Most inexperience trainees concerned at this weak point and need somebody to produce a safer instrument. Data from our small survey study of 200 medical and nursing students found that $80 \%$ of them needed a safer vaginal birth device. They reported that the rubber gloves were slippery when they came into 
contact with the amniotic fluid and caused the baby to slip out of their hand, especially in emergency situations. The suitable safety apparatus was not only the protection of newborn-fall, but also the improvement of their self-confidence in obstetrical training, if it was available.

Owing to this requirement, our research team has developed a newborn fall protection device designed with the first safety concept, and its structural engineering strength has been verified. After that, we sent the video of this innovation to a senior obstetrician, a senior pediatrician, and an experienced midwife nurse for validation and approval. The National Research Council of Thailand has also examined this apparatus and verified that our invention was suitable and valid for presentation at the International Invention Exhibition in 2016. This equipment, consisting of two components, one of which was a safety tray for newborns, and the other was a tray supporter for part one. The invention specifics were listed in the methodology section. Prior evidence has indicated that simulation trails improve self-confidence and obstetric skills (Dayal et al., 2009; Deering, Auguste, \& Lockrow, 2013; Goffman, Colleen, \& Bernstein, 2013) and patient outcomes. (Smith, Siassakos, Crofts, \& Draycott, 2013) Recent data have shown that simulation has had an impact on self-confidence and has led to the development of clinical skills. (Almeida et al., 2019) Therefore, if we set up a simulation study with a safer device, the self-reliance and clinical skills of volunteers could be improved.

In this experiment, we were therefore aiming to boost our undergraduate self-esteem in vaginal birth training on the basis of our survey data. We set up a simulation trial to prove our hypothesis. We have wished to see changes in their practical abilities.

\section{Methods}

\subsection{Objectives}

The aim of this study was to test the effect of the new safety apparatus on vaginal birth training, enhancing self-efficiency among medical students.

\subsection{Study Design}

This study was a randomized trial design that compared self- efficiency of medical students between the conventional method and the intervention add-on training.

\subsection{Settings}

\subsubsection{Population and Sample Size}

Our population was composed of 150 medical students at the clinical level who had been enrolled undergraduate students at Burapha University. The inclusion criteria were as follows: students who passed obstetrics and gynecology-I according to the medical doctor's curriculum, who did not have a physical disability, and who agreed to this simulation study. The sample size was calculated by G-Power program version 3.1.9.2 by the setting as follows: the effect size $=0.50, \alpha$ error probability $=0.05$, the power of test $(1-6)=0.80$, and two tails

The $\mathrm{H}_{0}$ hypothesis of this analysis was that "there was no statistically significant difference in self-efficiency between the traditional and intervention measures" and $\mathrm{H}_{1}$ "there was a statistically significant difference in self-efficiency between the conventional and intervention tests". Therefore, the calculated sample size was at least 34 . We also increased the number of volunteers by $15 \%$ in the event that volunteers were either withdrawn or unable to participate in the project all the time. For these reasons, a sample size of 40 was needed for this project. We picked samples from the student list by computerization, simply randomizing them and matching them to the inclusion criteria.

\subsubsection{What About the Safety Apparatus in This Study?}

My consultant and I have set up this safety device on the basis of student requirements. One thing in vaginal birth training that almost all of the undergraduates concerned was the unintentional fall of the newborn in the second stage of labor, especially in the first case. This equipment may therefore play a role in improving self-reliance and result in improved clinical performance. Before the invention, we had the medical and patent data checked and collected the data. We then developed the first prototype that went through the engineering test until it was ready to use. This invention is currently under consideration for intellectual property registration.

This invention consisted of two parts. The first was a baby tray [1] with a rectangular shape of $40 \times 60 \mathrm{~cm}$ and a raised edge of $10 \mathrm{~cm}$. The base of the baby tray was designed for liquid drainage through a pore of $1.5 \mathrm{~cm}$ on the bottom of one-third of the tray base. There was a tiny hose contact pipe at the bottom of the baby tray [2]. The second component was the baby tray holder with the upper rectangular case, which was half the size of the baby tray [4]. By wearing through the half-plate at the baby tray bottom, this portion was able to connect with the 
baby tray. [3] The baby tray was supported primarily by a single pillar [7] with height adjustable and screw locking knobs. [5, 6, 8] It also had a "U-shaped" platform [9] with four break-system wheels [10] for stability and mobility convenience (see Figures $1 \& 2$ ). The material for all the devices was stainless steel number $316 \mathrm{~L}$.

An engineering test was passed on to this apparatus. The results indicated that the equipment was strong and secure enough to be used in humans.

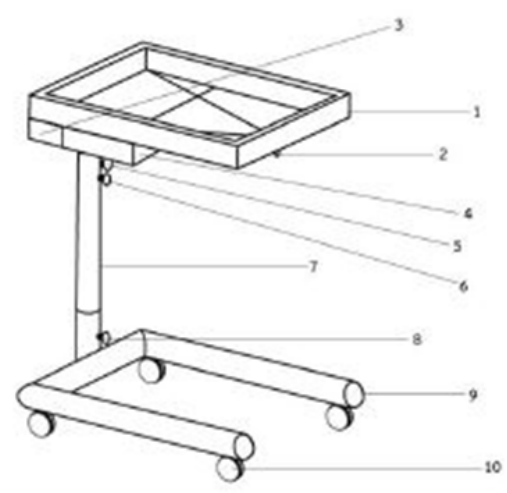

Figure 1. The newborn-fall prevention apparatus in 3 dimension illustration. There are two main parts. Part 1 is the baby tray [1] with hose connection [2]. Part 2 is the baby tray supporting which composes of rectangular box for baby support [4] and the single pillar [7] for adjustable height as required by screw-knobs. [5, 6, 8] The basement support is the U shape platform [9] with 4 wheels with break system [10]
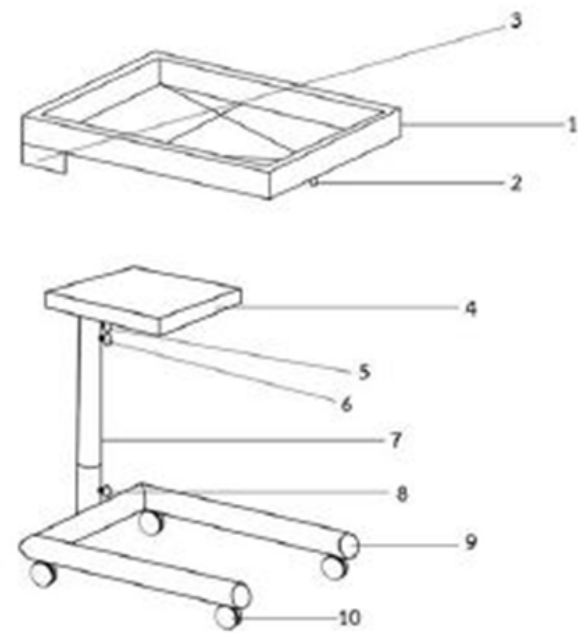

Figure 2. The newborn-fall prevention apparatus illustration of separation part in three dimension. The main part is raised edge rectangular baby tray [1] with drainage hose connection [2]. At the bottom of baby tray has two of half frame plates [3] for combination with the supporting box [4]. There is the single pillar [7] which height adjustable by screw-knobs $[5,6,8]$ and $\mathrm{U}$ shape platform [9] with 4 wheels with break system [10]

\subsubsection{Configuration of Mannequin-Based Simulation of Vaginal Birth}

The simulation scenario was a 25 -year-old pregnant woman was in the birth room. The vital signs were stable, and her cervical opening was fully dilated with spontaneous rupture of the fetal membrane. The presentation of the fetal head was +3 . Please help her deliver the baby only to complete the second stage of labor.

We provided two simulation birth stations, the traditional and the updated, with the equipment as similar as possible to the actual situation, in particular the newborn model and the simulation of maternal birth power. 
Threatening factors for new trainees are the slippery infant skin and the immense mother's push in the second stage of childbirth. As a result, we sprayed the newborn mannequin with a shampoo mixed with water and used the intermittent balloon pump to move the mannequin vigorously in this study. We set up the birth room by asking the midwives to cheer on vaginal birth.

In order to minimize the bias of self-reporting and the teacher-student effect on the evaluation of volunteers, we asked the president of the medical student association (MSA) from another neighboring medical school to perform this trial under our supervision, which had not been explained to volunteers before. In addition, we withheld the ownership of this invention from volunteers in order to reduce their bias in the evaluation of this research.

Volunteers were divided by random allocation into two groups to test both traditional and new intervention methods at the same time, and then volunteers re-tested the experiments by switching stations. After the volunteers finished each station, they had to assess their self-efficacy with the General Self Efficiency (GSE) scale format and send it back to our assistants before they moved out. The action time for each station was five minutes.

We invited the president of another MSA to orient our volunteers and instructed them to use the newborn-fall protection apparatus. During the trial of both methods, we invited obstetricians from another hospital who had worked for at least 10 years, including resident training, to observe and evaluate the clinical skill of volunteers using the Clinical Performance Assessment Tool (CPAT) scale. (Henderson, 2016) The assessors were in the experimental stations, but were hidden behind a wall with a viewfinder to track the volunteers without the volunteers notifying them. Around the same time, we recorded videos of both experiments in order to effectively assess them. The volunteers understood this research process and decided to join the project.

\subsubsection{Data Collection}

General data on participants, their views on this apparatus, and a comparison of their self-reliance between traditional and intervention trials were collected. We adapted the General Self-Efficiency Scale (GSE) of Schwarzer and Jerusalem 1995 (Schwarzer \& Jerusalem, 1995) to the Thai language for self-evaluation after finishing each station. We used the clinical performance scale to evaluate the volunteers simultaneously at both stations by clinical assessors.

\subsubsection{Data Analysis and Gathering of Expert Opinion Gathering}

The function of this apparatus was presented in picture diagrams, and the volunteers were asked to score this invention in five aspects. General data on volunteers were established using descriptive statistics. We compared General Self Efficience: GSE scores with a paired t-test.Throughout the simulation research, we planned to detect falling and near-missing events through video recording analysis. Two obstetricians were assigned to each station to assess their clinical performance of these volunteers on the CPAT scale. The mean score for CPAT was compared via paired t-test. After the data review, a meeting was held between researchers and experts (senior obstetricians, ergonomic designers, engineers, and senior midwives) for further editing and planning for further study.

\section{Results}

There were 40 medical students decided to enter the study. There were 17 males and 23 females in attendance. Most students were in their fourth year of study $(42.5 \%)$. The average total volume of vaginal delivery training was $6.49 \pm 1.4$ cases. Their mean \pm SD age was $22.88 \pm 2.73$ years. See Table 1 . All participants indicated that there was no newborn drop in the birth room during their previous training, but there were two cases of near-miss on the last training. The threatening factor that caused them to make the error came from a slippery newborn surface, inadequate safety apparatus, and weak self-confidence in practice.

The findings showed a substantial increase in the self-reliance of medical students with the intervention add-on in the simulation experiment $(\mathrm{t}=-9.92, \mathrm{p}<.01)$. Please see Table 2 . In addition, the mean clinical efficiency score was a statistically significant difference between the two studies. In the intervention trial, there was a higher scale. $(\mathrm{t}=-5.30, \mathrm{p}<.01)$. The CPAT scores of both assessors at the traditional and intervention stations were at the inexperienced (1.8) and assisted (2.36) stages, respectively. The conclusion seemed like this invention had a positive effect on the clinical competence of the simulation study. Please see Table 3.

The overall opinions of the volunteers on the five aspects of this innovation were at a good level (more than 3.5 points). The highest mean scores were for strength, followed by material, storage, convenience, and design, respectively. Please see Table 4. 
Throughout the simulation experiments, we found two falling events and four near-miss events in the traditional test and one falling event and three near-miss events in the intervention study. Please see Table 5. As the incident happened without safety measures during the study, the baby manikin dropped on the floor and the student showed fear and remorse.

Table 1. The general data of medical students volunteers in the vaginal birth simulation trials

\begin{tabular}{|c|c|c|c|}
\hline Topics & & $\mathbf{N}$ & Percentage \\
\hline \multicolumn{4}{|l|}{ gender } \\
\hline - male & & 17 & 42.50 \\
\hline - female & & 23 & 57.50 \\
\hline \multicolumn{4}{|l|}{ Study level } \\
\hline - $4^{\text {th }}$ & & 17 & 42.50 \\
\hline - $5^{\text {th }}$ & & 12 & 30.00 \\
\hline \multirow[t]{2}{*}{ - $6^{\text {th }}$} & & 11 & 27.50 \\
\hline & Minimum to Maximum & Mean & SD. \\
\hline Number of case ever delivered & 4 to 9 & 6.49 & 1.40 \\
\hline Age & 19 to 29 & 22.88 & 2.73 \\
\hline
\end{tabular}

Table 2. The comparison of the mean of self-efficacy score between conventional and intervention trial in medical students volunteer by paired t-test

\begin{tabular}{|c|c|c|c|c|c|c|c|c|}
\hline \multirow{3}{*}{ Pair 1} & \multicolumn{3}{|c|}{$\begin{array}{l}\text { Self-efficacy } \\
\text { assessment }\end{array}$} & \multicolumn{2}{|l|}{ Mean } & SD. & \multicolumn{2}{|c|}{ SE. } \\
\hline & \multicolumn{3}{|c|}{ Conventional } & \multicolumn{2}{|l|}{21.90} & 2.53 & \multicolumn{2}{|c|}{0.40} \\
\hline & \multicolumn{3}{|c|}{ Intervention } & \multicolumn{2}{|l|}{27.10} & 2.51 & \multicolumn{2}{|c|}{0.40} \\
\hline \multirow{4}{*}{$\begin{array}{l}\text { Paired } 1 \text { conventional trail } \\
\text { intervention trial }\end{array}$} & \multicolumn{8}{|c|}{ Paired differences } \\
\hline & \multirow[t]{2}{*}{ Mean } & \multirow{2}{*}{$\begin{array}{l}\text { SD. } \\
\text { o }\end{array}$} & \multirow[t]{2}{*}{ SE. } & $\begin{array}{l}95 \% \text { c } \\
\text { differen }\end{array}$ & e interval of & \multirow[t]{2}{*}{$\mathbf{t}$} & \multirow[t]{2}{*}{ df } & \multirow{2}{*}{$\begin{array}{l}\text { Sig } \\
(2- \\
\text { tailed) }\end{array}$} \\
\hline & & & & Lower & Upper & & & \\
\hline & -5.20 & 3.31 & 0.52 & -6.26 & -4.41 & -9.92 & 39 & 0.00 \\
\hline
\end{tabular}

Table 3. Clinical performance score of the volunteers on the simulation trail which rated by two clinical staffs

\begin{tabular}{|c|c|c|c|c|c|c|}
\hline Pair 1 & $\begin{array}{l}\text { Simulation } \\
\text { trial }\end{array}$ & Mean & $\mathbf{N}$ & SD. & & SE. \\
\hline & conventional & 3.90 & 40 & 1.03 & & 0.16 \\
\hline & Intervention & 4.72 & 40 & 0.93 & & 0.15 \\
\hline \multirow{4}{*}{$\begin{array}{l}\text { Paired } 1 \text { conventional } \\
\text { intervention trial }\end{array}$} & \multicolumn{6}{|c|}{ Paired differences } \\
\hline & \multirow[t]{2}{*}{ Mean } & \multirow[t]{2}{*}{ SE. } & $\begin{array}{l}95 \% \text { confidence interval of } \\
\text { differences }\end{array}$ & \multirow[t]{2}{*}{$\mathbf{t}$} & \multirow[t]{2}{*}{ df } & \multirow{2}{*}{$\begin{array}{l}\text { Sig } \\
(2- \\
\text { tailed })\end{array}$} \\
\hline & & & Lower & & & \\
\hline & -0.83 & 0.16 & -0.51 & -5.30 & 39 & 0.00 \\
\hline
\end{tabular}


Table 4. The opinions of medical student volunteers to the newborn-fall prevention apparatus which divided into five aspects

\begin{tabular}{llll}
\hline Opinions & N & Mean & SD. \\
\hline$-\quad$ Design & 40 & 4.10 & 0.50 \\
$-\quad$ Strength & 40 & 4.28 & 0.51 \\
$-\quad$ Convenience & 40 & 4.20 & 0.56 \\
$-\quad$ Material & 40 & 4.22 & 0.58 \\
$-\quad$ Storage & 40 & 4.20 & 0.56 \\
\hline Sum & $\mathbf{4 0}$ & $\mathbf{4 . 2 0}$ & $\mathbf{0 . 5 4}$ \\
\hline
\end{tabular}

Table 5. The number of accidental fall and near-miss fall events during the simulation test of vaginal delivery between conventional and intervention trial

\begin{tabular}{lllll}
\hline \multirow{2}{*}{ Events } & \multicolumn{2}{l}{ Conventional trial } & \multicolumn{2}{l}{ Intervention trial } \\
\cline { 2 - 5 } & number & percentage & number & percentage \\
\hline Falling event & 2 & 5.00 & 1 & 2.50 \\
\hline Near missed event & 4 & 10.00 & 3 & 7.5 \\
\hline
\end{tabular}

\section{Discussion}

As we all know, Human factors can influence the performance of an individual. This means that it impacts the safety of patients in the healthcare sector. Therefore, if we want more patient protection, you should better improve the system, particularly human resources management, than you did yesterday. A systematic review showed that shift work, extended working hours, and sleep deprivation of physicians resulted in adverse patient outcomes. (Mansukhani, Kolla, Surani, Varon, \& Ramar, 2012) While the Medical Council has introduced a policy that every physician should remain in duty for no longer than 24 consecutive hours, it is still impossible in practice, particularly for newly graduated physicians. Thus, inadvertent mistakes in medical procedures that were caused by inadequate professional abilities due to sleep deprivation were still present.

Which kind of way should we avoid it? Human error can occur at all-time even though we sleep; thus, the engineering system may be a one of solution. There have been many agreements for the application of engineering systems in the healthcare sector due to human factors. ("Challenges and Opportunities for Improving Patient Safety through Human Factors and Systems Engineering," 2018) This project was an example of adaptation to the patient safety engineering system. In the first phase, we needed to improve the pre-graduate self-efficacy of birth training, and the result showed a positive effect that met the objective. There was a significant statistical difference in self-confidence among participants. Most volunteers were satisfied to practice under safer conditions. They expected to use this invention in their future practice.

As recent data have shown, simulation learning has had an impact on the self-confidence and clinical performance of trainees in obstetric training. (Codsi, Nitsche, \& Brost, 2019; Gavin \& Satin, 2017; Satin, 2018) In this study, we have received evidence that there has been an improvement in the clinical performance of vaginal birth practices at the invention station. This could be explained by the positive effect of better self-confidence in volunteers. However, further studies are needed to prove this expectation.

My consultants and I searched the main patent data and found the devices that were invented in 1989. (Downs, 1989; Tramont, 1989) It was not easy, however; to practice this instrument. One used neonatal support nets that could harm the baby's fingers/toes and give rise to the risk of infection by spilling the body's secretion. Another was difficult to move and adapt in order to match the birth-bed and the client. Accordingly, our invention addressed this restriction by adding the firm material of this apparatus with good fluid drainage to the bottom of the tray. In addition, we placed the adjustable wheels at the base of the trolley and constructed an appropriate pillar that can be adapted to the bed height of the individual users. The first prototype was validated by senior medical staffs and nurses. This invention got a good level of rating score for volunteers' opinions. The highest and lowest mean scores were in strength and style, respectively. These findings could be explained by the "first security" concept in this innovation. As a result, the model shape had to be rectangular and wide enough to 
prevent the infant from falling. The style of this invention might therefore not look contemporary.

Data on video recording, we found falling and near-missing events in both trials. In the traditional trial, the number of these events was slightly higher. If you take this proportion in order to calculate the incidence, you will find a higher number of falling incidences in this trial. This study helped to claim that the incidence of infant-drop rates in hospitals often has not been reported or underestimated. This might cause undergraduates to become anxious and frightened when they had to deal with it.

Currently, patient safety is the first priority in medical practice. This issue does not only for graduates, but also for undergraduates. The World Health Organization: WHO also offered a guideline for integration into the medical curriculum for students in order to improve patient safety (Walton et al., 2010). This apparatus will therefore have a role to play in this policy. Medical safety devices provide not only the physical safety aspect, but also the psychological safety zone for all those involved. Many studies have highlighted the positive effects of self-confidence on competency improvements in medical students. ("ACOG Committee Opinion No. 358: professional responsibilities in obstetric-gynecologic education,” 2007; DiGiovanni et al., 2014; Maleki \& Patel, 2017; Malon et al., 2014; McNair, Griffiths, Reid, \& Sloan, 2016) According to our study, students' self-confidence was improved when applying our instrument to vaginal birth training. We hope that our invention will give this to other undergraduates as well.

What were the strengths and limitations of this study? This safety apparatus might be a pilot prototype for obstetrical medical innovations for medical/nursing practices in Thailand. Most medical devices are imported from Western countries. However, some devices must be resized and adapted for Asian sizes and cultures. Therefore, these devices were not compatible in some patients or in some situations. We believe that the research and development of medical devices should be designed for their consumers. We designed our appliance with the "apply for all" concept, in which the adjustable height and rotation tray were controlled by manual screw locking. This invention was therefore easy to apply to any patient-bed in vaginal delivery training. See Figures 1 and 2.

We also added a drainage orifice with a small pipe at the bottom of the baby tray for a hose connection because postpartum monitoring is one of the main indicators of hospital quality accreditation in Thailand. This device provides an option to accurately measure post-partum bleeding. Additionally, the engineering test confirmed that our device was strong and secure enough to support a large baby.

However, this apparatus may be useless in setting the position of non-lithotomy in the vaginal birth method. In Thailand, however, vaginal delivery training of undergraduates still uses the lithotomy position platform. Therefore, at this point, we hope that this apparatus would solve a defect.

The weakness in this study was the bias in participants 'self-evaluation, which might interfere with the reliability of the results. At this point, we also concerned and set the methodology to dilute this defect by anonymity. However, we could not hide the experiment process at all times, because students from other institutions that have contributed to this research might be familiar with these volunteers and might have discussed this research process before.

Ultimately, infant fall prevention in-hospital requires several elements, such as the competency of staffs, available tools, a good environment, and efficient work processes, particularly in learning to process. Medical errors are most often caused by carelessness, neglect, and lack of awareness that may result from the increased workload and fatigue from heavy work. The birth aid in this research is only partial fault protection; therefore, it is necessary to develop other systems to prevent such problems.

\section{Conclusions}

The innovation of the birth-aid in-hospital infant protection device has achieved its goal of improving the self-reliance of medical students in vaginal birth training. In addition, it improved clinical performance. However, our work has had some defects and requires further improvement, i.e. ergonomic design, easy storage, and lightweight material. Based on this research, we have learned a lot about how to improve the next model in order to provide more patient safety and user-friendly options. Finally, we hope that the concept of "patient safety" will remain in the minds of all healthcare providers.

\section{Glossary}

Fall means "to suddenly go down onto the ground or towards the ground without intending to or by accident"

Near miss means "a situation in which an accident almost happened" or "an attempt to do or achieve something that fails although it almost succeeds". 


\section{Acknowledgments}

We would like to thank the Dean of medical faculty, Burapha University, for supporting this research and the volunteers who participated in this study.

\section{Competing Interests Statement}

The authors declare that there are no competing or potential conflicts of interest.

\section{References}

Abike, F., Tiras, S., D"under, I., Bahtiyar, A., Uzun, O. A., \& Demircan, O. (2010). A new scale for evaluating the risks for in-hospital falls of newborn infants: a failure modes and effects analysis study. Int $J$ of Pediatr, 1-9. https://doi.org/10.1155/2010/547528

ACOG Committee Opinion No. 358: professional responsibilities in obstetric-gynecologic education. (2007). Obstet Gynecol, 109(1), 239-242. https://doi.org/10.1097/00006250-200701000-00056

Almeida, R., Mazzo, A., Martins, J. C. A., Jorge, B. M., Souza Júnior, V. D., \& Mendes, I. A. C. (2019). Self-confidence in the care of critically ill patients: before and after a simulated intervention. Rev Bras Enferm, 72(6), 1618-1623. https://doi.org/10.1590/0034-7167-2018-0758

Challenges and Opportunities for Improving Patient Safety through Human Factors and Systems Engineering. (2018). Health Affairs, 37(11), 1862-1869. https://doi.org/10.1377/hlthaff.2018.0723

Codsi, E., Nitsche, J. F., \& Brost, B. C. (2019). Chapter 30 - Simulation for Obstetrics. In G. Chiniara (Ed.), Clinical Simulation (Second Edition) (pp. 431-440). Academic Press. https://doi.org/10.1016/B978-0-12-815657-5.00030-9

Dayal, A. K., Fisher, N., Magrane, D., Goffman, D., Bernstein, P. S., \& Katz, N. T. (2009). Simulation training improves medical students' learning experiences when performing real vaginal deliveries. Simul Healthc, 4(3), 155-159. https://doi.org/10.1097/SIH.0b013e3181b3e4ab

Deering, S., Auguste, T., \& Lockrow, E. (2013). Obstetric simulation for medical student, resident, and fellow education. Semin Perinatol, 37(3), 143-145. https://doi.org/10.1053/j.semperi.2013.02.003

DiGiovanni, B. F., Southgate, R. D., Mooney, C. J., Chu, J. Y., Lambert, D. R., \& O'Keefe, R. J. (2014). Factors impacting musculoskeletal knowledge and clinical confidence in graduating medical students. $J$ Bone Joint Surg Am, 96(21), e185. https://doi.org/10.2106/JBJS.M.01283

Downs, M. C. (1989). United State of America Patent No. US4823418A. Lens.org.

Galuska, L. (2011). Prevention of In-Hospital Newborn Falls. Nurs Womens Health, 15(1), 59-61. https://doi.org/10.1111/j.1751-486X.2011.01611.x

Gavin, N. R., \& Satin, A. J. (2017). Simulation Training in Obstetrics. Clin Obstet Gynaecol, 60(4), 802-810. https://doi.org/10.1097/GRF.0000000000000322

Goffman, D., Colleen, L., \& Bernstein, P. S. (2013). Simulation in maternal-fetal medicine: Making a case for the need. Semin Perinatol, 37(3), 140-142. https://doi.org/10.1053/j.semperi.2013.02.002

Hantske, M. M. (2015). Preventing Newborn Falls. J Obstet Gynecol Neonatal Nurs, 44, S24-S25. https://doi.org/10.1111/1552-6909.12697

Helsley, L., McDonald, J. V., \& Stewart, V. T. (2010). Addressing in-hospital "falls" of newborn infants. Jt Comm J Qual Patient Saf, 36(7), 327-333. https://doi.org/10.1016/S1553-7250(10)36049-1

Henderson, W. R. (2016). Development of a clinical performance assessment tool for an occupational therapy teaching clinic. The Open Journal of Occupational Therapy, 4(3), 16. https://doi.org/10.15453/2168-6408.1217

Maleki, A., \& Patel, C. R. (2017). Improving medical students' confidence with supplemental training programs: a medical student's view. Adv Med Educ Pract, 8, 777-778. https://doi.org/10.2147/AMEP.S154221

Malon, M., Cortes, D., Andersen, J., Jensen, M. A., Mortensen, H. B., Nygaard, U., \& Greisen, G. (2014). Implementing video cases in clinical paediatric teaching increases medical students' self-assessed confidence. Dan Med J, 61(4), A4805.

Mansukhani, M. P., Kolla, B. P., Surani, S., Varon, J., \& Ramar, K. (2012). Sleep deprivation in resident physicians, work hour limitations, and related outcomes: a systematic review of the literature. Postgrad Med, 124(4), 241-249. https://doi.org/10.3810/pgm.2012.07.2583 
Marchetti, F., Eskenazi, B. e. b. e., Weldon, R. H., Li, G., Zhang, L., Rappaport, S. M., \& Wyrobek, A. J. (2012). Occupational Exposure to Benzene and Chromosomal Structural Aberrations in the Sperm of Chinese Men. Environ Health Perspect, 120(2), 229-234. https://doi.org/10.1289/ehp.1103921

McNair, R., Griffiths, L., Reid, K., \& Sloan, H. (2016). Medical students developing confidence and patient centredness in diverse clinical settings: a longitudinal survey study. BMC Med Educ, 16(1), 176. https://doi.org/10.1186/s12909-016-0689-y

Monson, S. A., Henry, E., Lambert, D. K., Schmutz, N., \& Christensen, R. D. (2008). In-hospital falls of newborn infants: Data from a multihospital health care system. Pediatrics, 122(2), E277-E280. https://doi.org/10.1542/peds.2007-3811

Satin, A. J. (2018). Simulation in Obstetrics. Obst Gynecol, 132(1), $199-209$. https://doi.org/10.1097/AOG.0000000000002682

Schwarzer, R., \& Jerusalem, M. (1995). Generalized Self-Efficacy Scale. Generalized Self-Efficacy Scale, 35-37. https://doi.org/10.1037/t00393-000

Smith, A., Siassakos, D., Crofts, J., \& Draycott, T. (2013). Simulation: Improving patient outcomes. Semin Perinatol, 37(3), 151-156. https://doi.org/10.1053/j.semperi.2013.02.005

Tramont, C. V. (1989). U.S.A Patent No. US 4880418 A. www.lens.org.

Walton, M., Woodward, H., Van Staalduinen, S., Lemer, C., Greaves, F., Noble, D., . . Barraclough, B. (2010). The WHO patient safety curriculum guide for medical schools. Qual Saf Health Care, 19(6), 542-546. https://doi.org/10.1136/qshc.2009.036970

\section{Copyrights}

Copyright for this article is retained by the author(s), with first publication rights granted to the journal.

This is an open-access article distributed under the terms and conditions of the Creative Commons Attribution license (http://creativecommons.org/licenses/by/4.0/). 